\title{
UNGARETTI ENTRE OSWALD DE ANDRADE, Blaise Cendrars, Haroldo de Campos: AFINIDADES E ASSIMETRIAS
}

\section{Lucia Wataghin}

O campo das relações Cendrars/Ungaretti/Oswald/Haroldo de Campos - um triângulo ítalo-franco-brasileiro de contatos, poesia e crítica de vanguarda - é muito rico. Pode-se estabelecer como ponto inicial a poesia francesa de Ungaretti (composta entre 1914 e 1919, dedicada a Apollinaire, Breton, Cendrars, Salmon, em parte traduzida por Haroldo de Campos) e continuar com as relações Ungaretti/Cendrars: além do poema "Roman Cinéma", de Ungaretti (1969b, pp. 360-362), dedicado a Cendrars, temos as cartas ao amigo Giovanni Papini (UNGARETTI, 1988), em que o autor descreve ou menciona o poeta franco-suíço, anos depois que ambos, Ungaretti e Cendrars, voltaram da guerra para seus respectivos países e compartilharam a experiência de voluntários no front. $\mathrm{Ou}$, ainda, pensar nas relações Ungaretti/ Haroldo de Campos: vejam-se os importantes ensaios de Haroldo sobre Ungaretti (CAMPOS, 1977, pp. 77-90; e UNGARETTI, 2003, pp. 187-194) e as traduções da sua poesia, desde Alegria até Últimos coros para a Terra Prometida (UNGARETTI, 2003).

No lado franco-brasileiro, há muitos testemunhos da forte impressão deixada por Cendrars no Brasil, suas amizades de São Paulo e do Rio (com Oswald, Tarsila, Mário de Andrade, Paulo Prado, Ronald de Carvalho, Sérgio Buarque de Hollanda e muitos outros), ${ }^{1}$ suas viagens, suas

\footnotetext{
${ }^{1}$ Muitos são citados na dedicatória de Feuilles de route (CENDRARS, 1924).
} 
colaborações com artistas brasileiros, seus textos dedicados inteiramente, ou em parte, ao Brasil (CENDRARS, 1976 e 2009). ${ }^{2}$ Temos ainda o triângulo Ungaretti/Cendrars/Oswald: as obras em destaque são Pau-Brasil de Oswald, publicada em Paris por sugestão de Cendrars, ${ }^{3}$ e Feuilles de route de Cendrars, ambas escritas em 1924, na fase da mais intensa colaboração entre seus autores, e ambas ilustradas por Tarsila do Amaral; e ainda Páu Brasil, a tradução/recriação italiana (UNGARETTI, 1961) de Pau-Brasil de Oswald. Acrescento ainda o prefácio de Ungaretti à tradução italiana das Memórias sentimentais de João Miramar (ANDRADE, 1970), confirmando o interesse e talvez a predileção do poeta italiano pela obra de Oswald dessa fase. Esse mesmo livro, por sua vez, foi prefaciado no Brasil com um estudo de Haroldo de Campos (ANDRADE, 1990), fundamental para interpretação e crítica da obra de Oswald.

Ao repensar as relações entre as literaturas italiana, francesa e brasileira, a presente reflexão não pode prescindir dos estudos de EvenZohar, que afirma a existência de relações hierárquicas (naturalmente flutuantes) entre sistemas literários que se encontram em comunicação. Segundo ele (que cita Tynianov), há uma luta constante entre os vários sistemas para a obtenção da "posição central" (EVEN-ZOHAR, 1995). No triângulo ítalo-franco-brasileiro que identificamos se reconhece, desde o começo, a predominância da França, seja em relação à literatura e cultura brasileiras, seja em relação ao próprio Ungaretti, notoriamente francófilo (e francófono). O que torna especialmente interessante essa encruzilhada de obras e autores é justamente o movimento da literatura brasileira, que tematiza nesse momento histórico sua própria luta para reverter a relação de dependência, especialmente em relação à literatura francesa.

A posição de Ungaretti no Brasil é a de um poeta que se relaciona naturalmente com outros escritores eartistas, e manifesta sua consideração pela literatura brasileira traduzindo e comentando as obras de poesia deles. Sua experiência brasileira é vasta, complicada pelo grave luto da morte do filho em solo brasileiro, e não pode ser resumida em poucas fórmulas, mas é curioso que sejam visíveis nela, sobretudo inicialmente, traços da mediação da cultura francesa. Até no trato pessoal isso se verifica: é significativo que Ungaretti preferisse conversar em francês, e não em italiano - como lembrou Antonio Candido (1991), em entrevista -, e que

${ }^{2}$ Entre os estudos dedicados especificamente a Cendrars no Brasil, vejam-se Amaral (1970) e Eulalio (1978).

${ }^{3}$ Cf. Eulalio (1978, p. 18). 
um breve filme gravado no saguão do prédio de História e Geografia da Universidade de São Paulo - USP, em 1967 ou 1968, mostrasse Ungaretti respondendo em francês à entrevista de Paulo Emílio Salles Gomes.

\section{VANGUARDAS E PRIMITIVISMO}

Um tema importante, no âmbito das relações que observamos entre os diversos países e culturas, e que mobiliza Ungaretti, Oswald, Tarsila, Cendrars e muitos outros, é o das relações entre vanguardas e primitivismo. É própria das vanguardas a polêmica contra a tradição, a oposição às convenções e ao academicismo por meio da invenção de uma língua nova, não contaminada, livre de compromissos com a arte "oficial". Pureza, incontaminação, mito das origens, primitivismo são todos temas que o modernismo brasileiro compartilha e em parte retoma das vanguardas europeias do começo do século XX. Em especial a arte primitiva negra, africana - redescoberta e admirada por Apollinaire, Picasso, Braque, Tzara, Vlaminck e muitos outros, ${ }^{4}$ pela sua extrema capacidade de síntese e pelo despojamento expressivo -, vai, desembocando no cubismo, participar de uma profunda revolução nas artes na Europa - e não apenas nas artes figurativas -, envolvendo também, com uma defasagem de cerca de quinze anos, ${ }^{5}$ os modernistas brasileiros.

Vale sempre dizer, como escreveu Antonio Candido, que, embora a cultura brasileira fosse mais predisposta - pela sua maior afinidade com as artes primitivas - a aceitar e assimilar as mudanças propostas pelos modernistas europeus, havia uma enorme sintonia entre as duas vanguardas: "É impressionante a concordância com que um Apollinaire e um Cocteau ressurgem, por exemplo, em Oswald de Andrade" (CANDIDO apud NUNES, 1979, p. 26). É fato pacífico, declarado pelo próprio Oswald numa conferência pronunciada em Paris, em 1923, que o primitivismo das vanguardas brasileiras foi inspirado "na revalorização das manifestações da arte negra, empreendida pelas vanguardas europeias” (ANDRADE apud

\footnotetext{
${ }^{4}$ Lembro que, como resume Benedito Nunes, os novos interesses surgem pela "ação conjunta da arqueologia e da etnologia modernas - uma trazendo as revelações da arte pré-histórica, outra o impacto da arte africana" (NUNES, 1979, p. 18).

${ }_{5}^{5}$ Consideramos como datas emblemáticas: 1907, o início do cubismo, ano da composição do quadro As demoiselles d'Avignon de Picasso; 1922, Semana de Arte Moderna em São Paulo. A primeira viagem de Oswald à Europa acontece em 1912, no mesmo ano da chegada de Ungaretti a Paris.
} 
BOAVENTURA, 1986, p. 46). E Mário de Andrade (2003, p. 9) também declarava: "Nós somos, na realidade, os primitivos de uma nova era". Esse gosto pelo despojamento, que está no ar na Europa, nas primeiras décadas do século, derivado do interesse pelas artes primitivas da África e da Oceania, manifesta-se na arte sintética, breve, lapidária da Alegria de Ungaretti, o que raramente é lembrado.

Mas o primeiro ato - explícito - importante de revalorização da arte negra na área da literatura foi realizado por Blaise Cendrars, o poeta franco-suíço que se tornou mais tarde amigo de Oswald e Tarsila. A Anthologie nègre de Cendrars (1947, pp. 3-4), lançada em 1919, é motivada pela exigência, declarada pelo autor no breve prefácio, de conhecer "as línguas e as literaturas das raças primitivas", pois esse conhecimento é "indispensável para a história do espírito humano". ${ }^{6}$ A Anthologie é uma compilação de contos africanos orais, reunidos e traduzidos para o francês por missionários, viajantes e exploradores, e desprovida, evidentemente, de precisão e caráter científico. Cendrars descreveu com vivacidade e bom humor, em O loteamento do céu, as condições em que, "sem ser um linguista nem ter querido (se) especializar", foi capaz de compilar, "em menos de um mês, as 350 páginas bem compactas do grosso volume de compilação que não devia render(-lhe) mais do que 400 francos" (CENDRARS, 1961, p. 322). (Bem humorado, ele acrescenta: "Mas, como chegaram em boa hora!" - p. 322). Apesar de seu caráter não científico (ou seja, pouco confiável pelos critérios e pelas condições da compilação), o livro, graças à personalidade de seu explosivo compilador, foi um marco fundamental na história da cultura e da arte (no mesmo ano, 1919, houve o primeiro congresso pan-africano, organizado pelo intelectual afroamericano W.E.B. Du Bois, e a primeira exposição de arte negra em Paris, organizada por Paul Guillaume, grande amigo de Apollinaire). ${ }^{7}$

Ainda a propósito da contribuição de Cendrars nesse momento histórico de descoberta e compreensão das artes e da linguagem "negras", lembro que Darius Milhaud - que reivindica o mérito de ter sido um dos primeiros, na Europa, a fazer uso do jazz, que na época era confinado aos bairros negros nos Estados Unidos - deve a Cendrars (1990, p. 7) o

\footnotetext{
6 “[...] nul n'est plus en droit d'ignorer en Europe que l'Afrique des Noirs est un des pays linguistiques les plus riches qui soient"; "l'étude des langues et de la littératures des races primitives est une des connaissances les plus indispensables à l'histoire de l'esprit humain". 7 Juntos, Guillaume e Apollinaire publicaram, em 1917, o livro Esculturas negras, um dos primeiros estudos sobre a arte da África e da Oceania.
} 
tema do seu balé $A$ criação do mundo (1922), retirado de um dos contos da Anthologie négre. Em sua primeira viagem ao Brasil, Cendrars (1976, p. 23) já tinha em sua bagagem "uma porção de contos negros que formarão o segundo volume da minha Antologia", esta que, porém, nunca saiu. Mas, anos depois, ele retomou o tema, com um volume de Pequenos contos negros (1928), um título para literatura infanto-juvenil, que ainda recentemente repercutiu no Brasil, numa bela edição ilustrada. ${ }^{9}$

Mas voltando à primeira Anthologie nègre, uma reação imediata à sua ideação (antes mesmo da publicação), no ambiente que nos interessa aqui, foi justamente a de Ungaretti. Naquele "mês" (ou pouco menos de um mês) de 1919 em que preparava sua Anthologie, Cendrars teve tempo ainda de projetar, com Ungaretti (1988), uma nova antologia negra, em italiano, feita do material não utilizado na primeira. $\mathrm{O}$ projeto foi apresentado a Giovanni Papini, a quem Ungaretti pediu que encaminhasse a proposta para o editor Vallecchi, mas isso não foi realizado, e dele restou, na produção de Ungaretti, apenas a tradução de um dos textos da Anthologie de Cendrars ("La danse des animaux", que Ungaretti traduziu com o título “Tam tam degli animali”) (UNGARETTI, 1936).

O tema primitivista em Ungaretti está presenteespecialmente em seus trabalhos (de poesia, tradução e crítica) que guardam alguma relação com o universo brasileiro: além dessa dança africana (traduzida muito antes de sua primeira viagem ao Brasil), há três fábulas cosmogônicas indígenas e um canto popular sertanejo, na antologia de traduções ungarettianas de poesia brasileira, e alusões ao mundo tropical, ou ao mundo amazônico, em suas coletâneas de ambiente brasileiro (A dor e Um grito e paisagens) e em cartas, discursos, artigos, ensaios relativos ao Brasil. Segundo Covizzi e Wataghin (2003, p. 190), a escolha ungarettiana de traduzir as fábulas cosmogônicas indígenas, apresentando-as como ponto inicial da poesia brasileira, por um lado se liga à ideia de origem, que é grande tema de Ungaretti e, por outro, é devida à leitura que ele faz da Pequena história da literatura brasileira, de Ronald de Carvalho (1984). O segundo capítulo desta obra, intitulado "A poesia e as lendas populares no Brasil", trata de "lendas e mitos" populares. O próprio Ronald de Carvalho está já sintonizado, nesse livro, com as vanguardas de Paris, o que se revela quando explica sua preferência pelos textos "de proveniência africana" -

\footnotetext{
${ }^{8}$ Esse é um verso - caracteristicamente prosaico - do poema Bagage.

9 Com tradução de Priscila Figueiredo, professora de literatura brasileira na USP, e ilustrações de Lygia Rocco, para a editora SM, São Paulo (2014).
} 
que ele contrapõe aos de origem europeia -, porque "aproximam-se mais de nossa alma" (CARVALHO, 1984, p. 62). Por outro lado, ressoa nessa ideia a memória da Anthologie négre e talvez até dos pequenos contos negros de Cendrars: o esforço de recuperação de um patrimônio oral, popular, originário, pouco conhecido e, como percebemos hoje talvez mais do que na época, gravemente ameaçado de extinção.

É preciso atentar para as peculiaridades da atitude de Ungaretti em relação aos movimentos de vanguarda: ele acompanha de perto tudo o que acontece de novo e importante no campo das artes em Paris, mas se conserva em posição autônoma e vai progressivamente declarando e aprofundando suas diferenças e suas críticas às teorias e às poéticas das vanguardas (especialmente futurismo e surrealismo). Nascido e crescido no Egito, longe do centro da tradição da poesia italiana e europeia, Ungaretti parece espontaneamente inovador e naturalmente livre de influências conservadoras; de fato, sua primeira poesia inaugura um movimento de profunda e vital ruptura das convenções da arte oficial. Mas sua condição de filho de emigrantes italianos no Egito, de volta, já adulto, ao país de origem dos pais, impõe também a exigência oposta, de reencontro com a palavra "em sua vida milenária", como diz muito claramente já em 1919, no prefácio à segunda edição de Il porto sepolto, em que esclarece suas filiações e suas dívidas (a inicial atração pelas "orgias, pesadelos, preciosidades dos simbolistas", o interesse, que não chega a ser adesão, pelas "palavras em liberdade" futuristas, e finalmente o retorno à "arte dos primórdios", à palavra que "ressuscitava, para [ele], em sua inteira vida milenária") (UNGARETTI, 1974, p. 15). ${ }^{10}$ Nesse mito das origens ungarettiano, o objetivo, afinal, é restaurar o estado primitivo de inocência, "recuar até o ponto de, pela memória, abolir a memória" (p. 15).

Essa é uma ideia de origem declaradamente viquiana ("o esquecimento iluminador", dom da memória, de Ungaretti corresponde à "robusta ignorância" dos antigos que, segundo Vico, seria a condição da criação), ${ }^{11}$ pela qual ambos os termos do binômio inocência e memória

\footnotetext{
${ }^{10}$ Em 1919, acontece a significativa adesão de Ungaretti à revista La Ronda, que propunha o retorno ao classicismo. Para um estudo aprofundado das complexas relações do poeta italiano com as vanguardas, veja-se Macrì (1995).

" "[...] quando o homem entende ele expande sua mente e compreende as coisas, mas quando não entende ele cria as coisas a partir de si mesmo, transformando-se nelas" [l'uomo con l'intendere spiega la sua mente e comprende esse cose, ma col non intendere egli di sé fa esse cose e, col transfomandovisi, lo diventa] (VICO, 1983, p. 346, axioma 405, tradução nossa).
} 
são igualmente importantes: $:^{12}$ se a inocência é o objetivo, a memória é o instrumento indispensável da poesia. Esse tipo de relação com a tradição (Ungaretti pensa sobretudo na tradição da poesia italiana) não é típico das vanguardas. A volta às origens, para ele, pode se identificar com a memória das paisagens egípcias de sua juventude, com "a arte dos primórdios", ou com as origens da poesia italiana ("o canto da língua italiana que eu buscava em sua constância através dos séculos”, o canto, como diz, "a batida do meu coração que eu queria sentir em harmonia com a batida do coração dos antepassados de uma terra por mim desesperadamente amada") (UNGARETTI, 1994, p. 200). Afinal, seu fim natural, o mais profundo e desejado fim - ou melhor, sua mais necessária função - para um poeta que tem fé absoluta na poesia, como ele, é o de tornar possível a criação.

A grande diferença entre Ungaretti e Oswald e Cendrars é a importância que cada um deles atribui à forma: ela é importantíssima para Ungaretti, que sempre foi um seu grande e estimado cultor, ao contrário de Oswald e Cendrars, ambos resistentes "à tentação da melodia, da serpente estética" (segundo a bela definição criada por Sérgio Milliet, a propósito do segundo). As críticas de Ungaretti às vanguardas apontam nesse sentido desde cedo; desde quando, por exemplo, observa que Cendrars e Max Jacob são "os únicos que têm da arte a ideia que é preciso ter: ainda que, um tanto amedrontados pela literatura, corrompam a inspiração com a ironia" (UNGARETTI, 1988, p. 243; carta de 1919).13 Há um desencontro (um respeitoso desencontro) entre a fé absoluta na poesia de Ungaretti (e a ausência de aberta polêmica e oposição à arte acadêmica) e a carga polêmica e irreverente das vanguardas.

\section{VIAGENS E RELAÇÃO COM O BRASIL}

Dito isso, para tentar definir melhor o lugar de Ungaretti no triângulo que ele forma com poetas e artistas de vanguardas em Paris (estando aí incluso Marinetti, não especialmente amado pelo nosso poeta), e com os modernistas brasileiros, podemos pensar nos desdobramentos das intensas e produtivas relações que se criaram nesse âmbito ou, mais em

\footnotetext{
${ }^{12}$ Com o título Innocence et memoire, Ungaretti publicará na França, com a tradução de Philippe Jaccottet, uma coletânea de ensaios de poética e crítica (Gallimard, 1968).

${ }_{13}$ "[...] i soli che abbiano dell'arte l'idea che ci vuole: per quanto ancora impauriti dalla letteratura, corrompano l'ispirazione in ironia”.
} 
geral, no âmbito das relações de Ungaretti com movimentos de vanguarda. Um segundo tema importante que envolve a todos é justamente a relação com o Brasil: "redescoberto" e revolucionado por Oswald, de volta de suas viagens à Europa, e visitado com olhos curiosos - atentos às diferenças, prontos a traçar analogias e contrastes, a comparar e opinar - pelos viajantes Cendrars e Ungaretti, vindos da Europa. Pensamos por exemplo nas descrições das chegadas ao Brasil. Na seção intitulada "Le formose", de Feuilles de route (CENDRARS, 1976a, p. 46), há versos:

Chegada a Santos.

Penetramos entre montanhas...

Entramos...

que ecoam, talvez involuntariamente, os primeiros versos da seção "História do Brasil", em Pau-Brasil (ANDRADE, 199ob, p. 69), em que Oswald cita, recriando, os textos dos antigos cronistas

Seguimos nosso caminho...

topamos aves...

houvemos vista de terra

e que Ungaretti (1961, p. 383) traduziu para o italiano:

Seguimmo di lungo il nostro cammino per questo mare

C'imbattemmo in uccelli

e udimmo vista di terra...

A simplicidade desses poemas que descrevem momentos memoráveis (a chegada dos colonizadores em Oswald é conotada com uma espécie de divertida solenidade, naturalmente ausente na descrição da chegada do turista Cendrars) é só aparente: o caminho dos versos é bem complexo e sofisticado, e os enriquece, em cada passagem, de um autor para os outros, com profundidade histórica e força crítica. Há temas comuns recorrentes nos três autores, estreitamente ligados às atitudes e juízos de valores implícitos ou declarados em relação à história, à tradição, àquilo que se imagina que sejam a força vital, a energia, a capacidade de inovação dos países envolvidos (França, Itália, Brasil). 
Desde a descrição da chegada ao Brasil, encontram-se também outros temas de encontro e desencontro dos viajantes, Ungaretti e Cendrars, com o novo país; um exemplo é o das estrofes do "Monologhetto" (UNGARETTI, 1969a) - dedicadas à sosta [parada, estadia] brasileira do autor -, cujos assuntos coincidem em muitos casos (com perspectivas diferentes) com os enfrentados por Cendrars em seus textos de ambientação brasileira. No Monologhetto, o poeta italiano comenta o calor insuportável em Pernambuco ("Si soffoca dal caldo: l'equatore è a due passi" [O calor é sufocante: estamos muito próximos da linha do equador] - p. 26o) assim como faz Cendrars, várias vezes ("O sol é estonteante; Insolação de um porto inteiro/ Nada mais do que o sol cruel e o calor que cai do céu e que sobe da água um calor alucinante"; "Nosso navio parece se derreter [...] no calor espesso”) (CENDRARS, 1976, pp. 46 e 47, respectivamente). Estão aí registradas as reações dos viajantes ao chegarem aos trópicos, uma série de choques e surpresas - nem todas agradáveis: o Natal no verão (as estações "inversas"), o excesso de calor, os insetos, a absoluta novidade nas paisagens e das sensações. Um texto exemplar de Cendrars, "Natal no Rio", comenta criticamente o "raciocínio" de um amigo, um universitário de Chicago com quem o escritor franco-suíço tomava uísque no roof garden do hotel Glória no Rio de Janeiro, no natal de 1953. Na conversa no bar, o americano, respondendo a uma pergunta do poeta, aplica à realidade brasileira as teorias tainianas, oferecendo um quadro desolante do Brasil e dos brasileiros:

“Então, a que conclusão você chega?”, perguntei a Sam.

"Não sei”, respondeu. "Devo concluir que a teoria de Taine da influência da paisagem, do habitat, da natureza, do ambiente geográfico sobre a literatura nacional de um país é falsa ou ultrapassada, ou devo considerar a ausência de uma filosofia especificamente brasileira no fenômeno da produção literária desta nação como um efeito do clima? O brasileiro não precisa de calor artificial. Não medita diante da lareira. Ele faz a sesta. O que explica sua credulidade, sua falta de energia, suas visões, seu infantilismo etc." (CENDRARS, 1976, p. 41).

Não é o caso hoje de confutar essas teorias em voga na época, por mais nocivas que tenham sido, mas vale registrar a manifestação de Cendrars, que responde ao amigo aludindo, um tanto vagamente, à pobreza na cidade do Rio e revelando sua própria impaciência para com a lógica do scholar americano ("Mas que ideia vir ao Rio para expor ideias. O simples fato de existir é uma verdadeira felicidade [...] Desde então, eu desconfio da lógica") (CENDRARS, 1976, p. 41). 
Os assuntos coincidentes Ungaretti/Cendrars são muitos e poderiam ser aprofundados: além de manifestarem estranhamento pelo Natal no verão (UNGARETTI, 1974, pp. 430-431; CENDRARS, 1976, pp. 40-41), ambos descrevem a vida a bordo dos navios: em "A bord du Formose", de Cendrars (1924, p. 201), encontram-se emigrantes russos, judeus, portugueses, espanhóis que falam todas as línguas, tocam vários instrumentos, cantam e dançam; de modo semelhante, a bordo do Neptunia, no "Monologhetto" de Ungaretti, dança-se sem parar num carnaval frenético e selvagem. A vida dos emigrantes nos navios e nos portos, durante as viagens, que encontramos em Cendrars ("Les pauvres émigrants qui attendent que les autorités viennent à bord" - CENDRARS, 1924, p. 197) é descrita também em poemas da primeira fase de Ungaretti (em que ele lembra sua própria viagem de emigração, do Egito à Europa). ${ }^{14}$

\section{O CONTRASTE ENTRE O VELHO E O NOVO}

O debate fundamental entre o Velho e o Novo (e a contribuição do primitivismo para o Novo) está embutido quase que em cada palavra e imagem dos autores no intenso clima vanguardista brasileiro. Oswald, com suas paisagens anticonvencionais - como a fulminante, geométrica paisagem de "Noturno. Lá fora o luar continua/ E o trem divide o Brasil / Comoum meridiano" (ANDRADE, 199ob, p. 91), ou suas paisagens cubistas, como o poema "Bucólica" (p. 92) - aparece sorridente, mas dificilmente deixa de integrar, até nas mais aparentemente inocentes paisagens, um conteúdo de denúncia e crítica da violência dos senhores contra os escravos e da lógica mercenária dos donos das terras. Em "Prosperidade", a riqueza do café, "o ouro silencioso" (p. 91), é associada à escravidão; as louvações da abundância da natureza são ironicamente desmistificadas. E lemos sarcasmo na reescritura oswaldiana da carta de Fernão Dias Paes, que conta as expedições de seus bandeirantes: "Vossa Senhoria/ Deve

\footnotetext{
${ }^{14}$ Cf., por exemplo, os versos: "Orizzonte d'oceano cinque nottate contemplato/ sdraiato a prua accanto a emigranti soriani/ donne botti uomini pertiche bimbi fagotti”, extraídos de uma variante de "Nebbia", que é por sua vez uma variante do poema "Levante", que se encontraagora em "L'Allegria” (UNGARETTI, 1969b, pp. 853-854). Talvez seja intermediário, entre Cendrars e Ungaretti, o poema “Zone”, de Apollinaire (1979, p. 96, cf. versos 121-128). Apollinaire usa exatamente a expressão de Cendrars: “ces pauvres émigrantes”. Luciano Rebay (1962, pp. 77-80) observou as relações entre os versos de "Zone" e os de uma antiga versão de "Levante", com o título "Le suppliche" (1915).
} 
considerar que este descobrimento/ É o de maior consideração/ Em rasam do muyto rendimento/ E também esmeraldas" (ANDRADE, 199ob, p. 78).

Cendrars (1976, pp. 58 e 64, respectivamente), por sua vez, celebra entusiasticamente o novo, encarnado no Brasil:

São Paulo. Enfim algumas fábricas um subúrbio um bondinho simpático

Condutos elétricos

Uma rua cheia de gente que vai fazer suas compras de tarde

[...];

São Paulo. Adoro esta cidade

São Paulo do meu coração

Aqui nenhuma tradição

Nenhum preconceito

Antigo ou moderno

Esses são exemplos entre muitos. As "fotografias verbais" paubrasileiras de Cendrars - segundo Haroldo de Campos, fotografias tiradas com uma "kodak excursionista" (CAMPOS, 1990, p. 34) (15 $^{15}$ são provavelmente, como pensa Haroldo, menos atentas do que as de Oswald às contradições da realidade brasileira e, por outro lado, também profundamente diferentes das dramáticas paisagens brasileiras de Ungaretti, permeadas de dor pela morte do filho. Nas paisagens de "A dor", o contraste velho/novo é representado pelos binômios Itália/Brasil e história/natureza, simbolizados, por exemplo, pelo pinheiro italiano, "hóspede almejado de pedras memoriosas" (UNGARETTI, 2003, p. 145), com que se reconhece de volta à pátria e pela gigantesca araucária brasileira, imagem infernal - uma entidade que devora outras vidas, "Refratária, mais que as outras condenadas, / A boca fresca de mato e borboletas" (p. 151).

"Primitivo" e "novo" talvez se encontrem sobretudo na maravilhosa abundância e variedade da natureza primordial brasileira, redescoberta pelos modernistas. Por exemplo, a ungarettiana Semantica (UNGARETTI, 1969b) poderia ser lida em relação a "Botânica", de Cendrars, como sugere Isabel Violante Picon (1998, p. 103), e - eu acrescento - a "Ignorância" (CENDRARS, 1976, p. 57). E quiçá ainda com outros poemas de Feuilles de

15 Vale a pena lembrar que nesse ensaio introdutório de Haroldo de Campos (1990, pp. 3134) ao Pau-Brasil há uma pequena seção intitulada "Oswald e Blaise Cendrars". 
route, livro escrito na fase da maior colaboração Cendrars/Oswald, e com o próprio Pau-Brasil de Oswald. Da leitura comparada dessas obras surge um quadro vivo e complexo das diferentes reflexões dos autores sobre a natureza imensamente vária do Brasil e as diferentes atitudes possíveis do brasileiro novo, do antigo colonizador e do novo viajante para com ela.

Cendrars declara sua satisfação por não conhecer todas as variedades, ou nenhuma, e pela absoluta novidade que encontra no Brasil; Ungaretti reclama dolorosamente pelo excesso de novidades ("É troppo azzurro questo cielo australe, / Troppi astri lo gremiscono, / Troppi e, per noi, non uno familiare"). ${ }^{16}$ Quanto ao Pau-Brasil de Oswald, suas fórmulas não deixam dúvidas sobre sua posição em relação ao novo: "Contra a cópia, a invenção e a surpresa" (ANDRADE, 199ob, p. 66).

\section{REFERÊNCIAS}

AMARAL, Aracy A. Blaise Cendrars no Brasil e os modernistas. São Paulo: Livraria Martins Editora, 1970.

ANDRADE, Mario de. Prefácio interessantíssimo. In: Pauliceia desvairada. Caixa modernista. São Paulo / Belo Horizonte: Edusp / UFMG Imprensa Oficial, 2003. Arquivo Mário de Andrade. IEB/USP: 9.

ANDRADE, Oswald de. Memorie sentimentali di Giovanni Miramare. Trad. Giovanni Cutolo, prefácio de Giuseppe Ungaretti. Milão: Feltrinelli, 1970.

ANDRADE, Oswald de. Memórias sentimentais de João Miramar. Introdução ("Miramar na mira”) de Haroldo de Campos. São Paulo: Globo, $1990 a$.

ANDRADE, Oswald de. Pau-Brasil. Fixação de textos e notas de Haroldo de Campos. São Paulo: Globo/Secretaria de Estado da Cultura, 199ob.

APOLLINAIRE, Guillaume. Poesie. Milão: Biblioteca Universale Rizzoli, 1979.

BOAVENTURA, Maria Eugenia. O projeto Pau-Brasil: nacionalismo e inventividade. Remate de Males, Campinas, n. 6, 1986, pp. 45-52.

CAMPOS, Haroldo de. Ungaretti e a estética do fragmento. In: A arte no horizonte do provável. São Paulo: Perspectiva, 1977, pp. 77-90.

\footnotetext{
16 "Há demasiado azul no céu austral / Astros demais o estorvam / Demais, e para nós nenhum é familiar" (UNGARETTI, 2003, p. 203, nota 15).
} 
CAMPOS, Haroldo de. Uma poética da radicalidade. In: ANDRADE, Oswald de. PauBrasil. Fixação de textos e notas de Haroldo de Campos. São Paulo: Globo/Secretaria de Estado da Cultura, 1990.

CAMPOS, Haroldo de. Ungaretti: o efeito de fratura abissal. In: UNGARETTI, Giuseppe. Daquela estrela à outra. Trad. de Haroldo de Campos e Aurora Bernardini. Lucia Wataghin (org.). São Paulo: Ateliê, 2003, pp. 187-194.

CANDIDO, Antonio. Entrevista concedida a Lucia Wataghin (oral). São Paulo, 15/o6/1991. (inédita)

CARVALHO, Ronald de. Pequena história da literatura brasileira. Belo Horizonte: Editora Itatiaia, 1984[1919].

CENDRARS, Blaise. Feuilles de route. Paris: Editions Sans Pareil, 1924.

CENDRARS, Blaise. Anthologie négre. Paris: Corréa, 1947.

CENDRARS, Blaise. Du monde entier. Poésies complètes 1912-1924. Préface de Paul Morand. Paris: Éditions Gallimard, 1967.

CENDRARS, Blaise. etc..., etc... (um livro 100\% brasileiro). Equipe de realização: Teresa Thiériot, Alexandre Eulálio, Carlos Augusto Calil. São Paulo: Perspectiva, 1976.

CENDRARS, Blaise. Antologia negra. Ciudad de La Habana: Editorial Arte y Literatura, 1990.

CENDRARS, Blaise. L'Eubage. Aux antipodes de l'unité. Paris: Honoré Champion Éditeur, 1995.

CENDRARS, Blaise. Au coeur du monde. Poésies complètes 1924-1929. Paris: Gallimard, 1997.

CENDRARS, Blaise. O loteamento do céu. Trad. Geraldo Holanda Cavalcanti. Coordenação editorial e prefácio Carlos Augusto Calil. São Paulo: Companhia das Letras, 2009.

CENDRARS, Blaise. Pequenos contos negros. Trad. Priscila Figueiredo, ilustrações Lygia Rocco. São Paulo: SM, 2014.

COVIZZI, Lenira Marques \& WATAGHIN, Lucia. Ungaretti tradutor discreto e a analogia entre os poetas árcades Tomás Antônio Gonzaga e Giovanni Meli. Revista de Italianística, VI-VII, 2003, pp. 181-198.

EULALIO, Alexandre. A aventura brasileira de Blaise Cendrars. São Paulo / Brasília: Edições Quiron / Instituto Nacional do Livro, 1978.

EVEN-ZOHAR, Itamar. Letteratura e polisistema letterario. In: NERGAARD, Siri (org.). Teorie contemporanee della traduzione. Milão: Bompiani, 1995, pp. 225-238. 
Ungaretti entre Oswald de Andrade, Blaise Cendrars, Haroldo de Campos... - 984

MACRİ, Oreste. Ungaretti e le avanguardie. In: Giuseppe Ungaretti 1888-1970. Atti del Convegno Internazionale di Studi. Alexandra Zingone (org.). Roma: ESI, 1995, pp. 57-79.

NUNES, Benedito. Oswald canibal. São Paulo: Perspectiva, 1979.

PICON, Isabel Violante. "Une oeuvre originale de poésie”. Giuseppe Ungaretti traducteur. Paris: Presse de l'Université de Paris-Sorbonne, 1998.

REBAY, Luciano. Le origini della poesia di Ungaretti. Roma: Edizioni di Storia e Letteratura, 1962.

UNGARETTI, Giuseppe. Traduzioni. St-John Perse, William Blake, Gongora, Essenin, Jean Paulhan, Affrica. Roma: Novissima, 1936.

UNGARETTI, Giuseppe. Il deserto e dopo. Prose di viaggio e saggi. Milão: Arnoldo Mondadori Editore, 1961.

UNGARETTI, Giuseppe. Monologhetto. In: Vita d'un uomo. Tutte le poesie. Milão: Mondadori, 1969a.

UNGARETTI, Giuseppe. Vita d'un uomo. Tutte le poesie. Milão: Mondadori, 1969b.

UNGARETTI, Giuseppe. Vita d'un uomo. Saggi e interventi. Milão: Mondadori, 1974.

UNGARETTI, Giuseppe. Lettere a Giovanni Papini 1915-1948. Maria Antonietta Terzoli (org.). Milão: Mondadori, 1988.

UNGARETTI, Giuseppe. Razões de uma poesia. Trad. Liliana Laganá, Lucia Wataghin, Maria Betânia Amoroso. Lucia Wataghin (org.). São Paulo: Edusp / Imaginário, 1994.

UNGARETTI, Giuseppe. Daquela estrela à outra. Trad. Haroldo de Campos e Aurora Bernardini. Lucia Wataghin (org.). São Paulo: Ateliê, 2003.

VICO, Giambattista. Autobiografia poesie scienza nuova. Milão: Garzanti, 1983. 